\title{
Saliva as a diagnostic tool: a review
}

\author{
Dr.Suhail majid ${ }^{1}$ Dr. Munaza shafi ${ }^{2}$ \\ ${ }^{1}$ (Associate Prof.\& HOD, deptt of periodontics. Govt. dental college, sgr) \\ ${ }^{2}$ (P.G.Student, deptt of periodontics. Govt. dental college, sgr)
}

\begin{abstract}
Saliva has been described as the mirror of the body. In a world of soaring healthcare costs and an environment where rapid diagnosis may be critical to a positive patient outcome, saliva is emerging as a viable alternative to blood sampling. As a diagnostic fluid, saliva offers distinctive advantages over serum because it can be collected non-invasively by individuals with modest training.Furthermore; saliva may provide a costeffective approach for the screening of large populations. In the field of periodontology, traditional clinical criteria are often insufficient for determining sites of active disease, for monitoring the response to therapy, or for measuring the degree of susceptibility to future disease progression. Saliva, as a mirror of oral and systemic health, is a valuable source for clinically relevant information because it contains biomarkers specific for the unique physiologic aspects of periodontal diseases as well as systemic diseases. This review highlights the various potentials of saliva as a diagnostic biomarker for oral and systemic diseases.
\end{abstract}

Keywords: Biomarkers, Saliva, diagnosis

\section{Introduction}

The second most common oral diseases next to dental caries are the periodontal diseases which are considered to be inflammatory disorder that damages tissue through the complex interaction between periopathogens and the host defence systems ${ }^{(1)}$ Because of the increasing prevalence and associated co morbidities ${ }^{(2)}$ screening and diagnostic modalities for the early identification of oral disease initiation and progression, as well as objective measures for response to therapy, are being sought. In oral diagnostics, it has been a great challenge to determine biomarkers for screening and predicting the early onset of disease (prognostic tests) or evaluating the disease activity and the efficacy of therapy (diagnostic tests). An oral diagnostic tool, in general, should provide pertinent information for differential diagnosis, localization of disease and severity of infection. It serves as a basis for treatment planning and provides a means for assessing the effectiveness of therapy. Current clinical diagnostic parameters that were introduced more than half a century ago continue to function as the basic model for oral diagnosis in today's clinical practice.

A biomarker, or biological marker, is in general a substance used as an indicator of a biological state in oral diagnostics; it has been a great challenge to determine biomarkers for screening, prognosis and evaluating the disease activity and the efficacy of therapy (diagnostic tests). An oral diagnostic tool, in general, should provide pertinent information for differential diagnosis, localization of disease and severity of infection. Traditional diagnostic measures, such as visual examination, tactile appreciation, periodontal pocket depth, attachment level, and plaque index, bleeding on probing and radiographic assessment of alveolar bone loss are still popular and universally used, however they are almost 50 years old and still act as basis for oral diagnosis till date.Saliva is simple, non-invasive, readily available and easily collected without specialized equipment or personnel. For the past two decades, saliva has been increasingly evaluated as a diagnostic fluid for detecting breast cancer $^{(3)}$, oral cancer ${ }^{(4)}$ caries risk ${ }^{(5)}$, salivary gland diseases ${ }^{(6)}$, periodontitis ${ }^{(7)}$, and systemic disorders such as hepatitis $\mathrm{C}$ and the presence of human immunodeficiency virus (HIV) ${ }^{(8)}$.

The various salivary biomarkers are as follows.

\section{Specific markers}

\section{Markers affecting the dental biofilm}

Immunoglobulins (Ig) are important specific defense factors of saliva. The predominant immunoglobulin in saliva is secretory $\operatorname{IgA}(\operatorname{sg} \mathrm{A})$, which is derived from plasma cells in the salivary glands. Lesser amount of $\operatorname{IgG}$ and $\operatorname{IgM}$ are also found in saliva. $\operatorname{IgA}, \operatorname{IgG}$, and $\operatorname{IgM}$ influence the oral microbiota by interfering with the bacterial adherence or by inhibiting bacterial metabolism ${ }^{(9)}$ There are two subclasses of IgA: $\operatorname{IgA} 1$ and $\operatorname{IgA} 2$. $\operatorname{IgA} 1$ is predominant in serum while $\operatorname{IgA} 2$ is found in higher concentrations in external secretions, that is, tears, saliva, and milk ${ }^{(10)}$

Many studies have been attempted to determine a relationship between salivary levels of $\operatorname{sig} \mathrm{A}$ and various forms of periodontal diseases. It was found that there was a positive correlation between the severity of inflammation and IgA concentration $\underline{(11, \underline{12})}$ 
Specific immunoglobulins in saliva directed toward periodontal pathogens have also been examined for their diagnostic potential. Eggert et al ${ }^{.(13)}$ reported that saliva from treated periodontitis patients had higher IgA and IgG levels to periodontal pathogens porphyromonas. gingivalis and Treponema. denticola than as compared to saliva from control subjects. Sandholm et al found increased concentrations of salivary IgG to Aggregatibacter. actinomycetemcomitans in patients of aggressive periodontitis

\section{Nonspecific markers}

Mucins are glycoproteins produced by Submandibular and sublingual salivary glands and numerous minor salivary glands. The physiological functions of the mucins (MG1 and MG2) are cytoprotection, lubrication, protection against dehydration and maintenance of viscoelasticity in secretions. The mucin, MG2, affects the aggregation and adherence of bacteria and is known to interact with Aggregatibacter actinomycetemcomitans, and a decreased concentration of MG2 in saliva may increase colonization with this periodontopathogens ${ }^{(14)}$.

Lysozyme is an antimicrobial enzyme with the ability to cleave chemical bonds in the bacterial cell wall. It can lyse some bacterial species by hydrolyzing glycosidic linkages in the cell wall peptidoglycan. It may also cause lysis of bacterial cells by interacting with monovalent anions and with proteases found in saliva. This combination leads to destabilization of the cell membrane, probably as a result of the activation and deregulation of endogenous bacterial autolysins. Patients with low levels of lysozyme in saliva are more susceptible to plaque accumulation, which is considered a risk factor for periodontal disease ${ }^{(15)}$.

Lactoferrin is an iron-binding glycoprotein produced by salivary glands, which inhibits microbial growth by sequestering iron from the environment, thus depriving bacteria of this essential element. Lactoferrin is strongly up-regulated in mucosal secretions during gingival inflammation and is detected at a high concentration in saliva of patients with periodontal disease compared with healthy patients ${ }^{(16) .}$

Histatin is a salivary protein with antimicrobial properties and is secreted from parotid and Submandibular glands. It neutralizes the endotoxic lipopolysaccharides located in the membrane of gram-negative bacteria. Histatin is also an inhibitor of host and bacterial enzymes involved in the destruction of the periodontium. In addition to its antimicrobial activities, histatin is involved in the inhibition of the release of histamine from mast cells, affecting their role in oral inflammation ${ }^{(17,18)}$.

Peroxidase is a salivary enzyme produced by acinar cells in the salivary glands. This enzyme removes toxic hydrogen peroxide produced by oral microorganisms and reduces acid production in the dental biofilm, thereby decreasing plaque accumulation and the establishment of gingivitis and caries. Patients with periodontal disease have demonstrated high levels of this enzyme in saliva ${ }^{(19) .}$

\section{Salivary proteomics for existing periodontal diseases}

Salivary Proteomic Biomarkers Variable amounts of blood, serum, serum products, GCF, electrolytes, epithelial and immune cells, microorganisms, bacterial degradation products, lipopolyscaaharides, bronchial products and other foreign substances are present in whole saliva ${ }^{.(2)}$ This makes saliva, the best periodontal diagnostic tool. Periodontal inflammatory mediators and tissue destructive molecules have been detected in the gingival tissues, GCF and saliva of patients affected by periodontitis ${ }^{(21,22,23)}$ Saliva contains biomarkers specific for the unique physiological aspects of periodontitis, and qualitative changes in the composition of these biomarkers could be diagnostic. It contains a wide variety of periodontal proteomic markers from immunoglobulins to bone remodeling proteins.

Interleukin (IL) $\mathbf{1 \beta}$ is a proinflammatory cytokine that stimulates the induction of adhesion molecules and other mediators which in turn facilitate and amplify the inflammatory response. Its levels correlated significantly with periodontal parameters after adjusting for the confounders.Moreover, combined levels of Il-1 $\beta$ and matrix metalloproteinase (MMP)-8 increased the risk ofexperiencing periodontal disease by 45 folds. ${ }^{(23)}$

MMPs- MMP-8 a key enzyme in extracellular collagen matrix degradation, derived predominantly from PMNs during acute stages of periodontal disease also correlated significantly with periodontal activity even after adjusting for the confounders, Moreover, its presence significantly increased the risk of periodontal disease (odds ratios in the 11.3-15.4 range). ${ }^{(23)}$ MMP-1 (interstitial collagenase) also appeared to be activated in periodontitis ${ }^{(23)}$ Consequently, quantification of the level of MMP-8 is a promising candidate for diagnosing and, possibly more importantly,predicting the progression of this episodic periodontal disease. Strong correlations between MMP-8 and traditional periodontal diagnostic methods further support the contention that MMP-8 is not only an indicator of disease severity, but also disease activity. Additionally, higher levels of other MMPs, including MMP-2, MMP-3 and MMP-9,were also reported in the saliva of patients affected by periodontitis. 


\section{Salivary proteases as biomarkers for premalignant and malignant oral lesions}

Oral squamous cell carcinoma (OSCC) accounts for more than 90 percent of oral cancers worldwide. It is particularly lethal, with a five-year survival rate post-diagnosis that hovers below 50 percent and has not improved in three decades. Its survival rates increase significantly when it is detected and treated early. Unfortunately, clinicians now lack tests which easily and reliably distinguish pre-malignant oral lesions from those already transitioned to malignancy. Enhancements in the area of early diagnosis, therefore, are the key to making strides against the disease. Numerous candidate proteins were discovered in saliva of patients with oral lesions, however, not all proteins have biomarker ability in diagnosing oral cancers. Bioinformatic analysis of exfoliated epithelial cells from subjects' saliva revealed increased myosin and actin abundance in those with malignant lesions as confirmed by western blotting. Salivary actin and myosin abundances distinguish oral lesion types with sensitivity and specificity rivaling other noninvasive oral cancer tests. These findings provided a promising starting point for the development of noninvasive and inexpensive salivary tests to reliably detect oral cancer early. ${ }^{(24)}$

A recent study stated that subtractive proteomics revealed several salivary proteins at differential levels between the OSCC patients. Five candidate biomarkers- M2BP, MRP14, CD59,profilin and catalase were successfully validated using immunoassays on an independent set of OSCC patients and matched healthy subjects. They concluded that patient-based saliva proteomics is a promising approach to searching for OSCC biomarkers. The discovery of these new targets may lead to a simple clinical tool for the noninvasive diagnosis of oral cancer ${ }^{(25)}$ IL- 6 and IL-8 areinvolved in the pathogenesis of OSCC, and havebeen linked with increased tumor growth and metastasis, hence its levels could serve as informative biomarkers for OSCC in saliva ${ }^{(26)} \mathrm{A}$ new study published by researchers at the UCLA School of Dentistry substantiates the effectiveness of measuring the microRNAs present in saliva to detect OSCCs. MicroRNAs are the molecules produced by cells that simultaneously assess the behavior of multiple genes and control their activity.

\section{Saliva As A Biomarker Of Systemic Disease}

The literature concerning the area of psychosocial stress and particularly the measurement of salivary free cortisol and $\alpha$-amylase are vast and specialised, and therefore beyond the scope of this review. We will concentrate on nonstress-related systemic pathologies.

It has been suggested by some that saliva can be viewed as "the mirror of the body" ${ }^{\text {"(27), }}$ reflecting the body's general state of health. In fact, it is now known that many substances found in peripheral blood are also found in saliva, although generally lower concentrations are found in saliva than in blood ${ }^{(28) .}$ With the emergence of new and highly sensitive technologies, it is now possible to analyse minute quantities of substances in human saliva. Proteomics technologies have allowed the determination of over 1,000 proteins in human whole saliva ${ }^{(29) .}$ Interestingly, around $22 \%$ of these proteins were unique to either the parotid or the submandibular/sublingual salivary glands suggesting that there are likely to be distinct differences in functions of the exudate secreted from the major salivary glands. The salivary transcriptome has been even more diverse than the proteome, with over 3,000 mRNAs so far identified in normal human saliva ${ }^{(30)}$. One study used four of these salivary mRNAs $(I L-8, O A Z 1, S A T$, and $I L 1 \beta)$ as biomarkers for the determination of oral cancer, with an overall hit rate of $91 \%$. Crucially, for the success of saliva as a viable biological fluid for the detection of oral cancers, salivary gene expression was found to be a more sensitive indicator of predicting disease (in this case oral cancer) than blood ${ }^{(31)}$ It is hoped that distinct mRNA groups or "signatures" will be identified in the future that act as biomarkers of the major systemic diseases ${ }^{(32) .}$ This approach, combined with a rapid sampling and

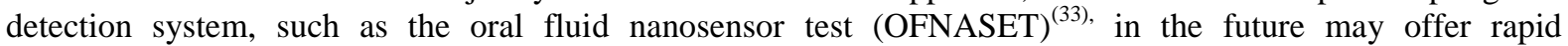
determination and diagnosis of major human diseases without the need for blood to be drawn from the patient, and alleviate a lengthy and anxious waiting period.

\section{Detection of Systemic Cancers in Saliva}

Elevated levels of the cancer antigen 15-3 (CA15-3) were detected in the saliva of women diagnosed with breast cancer compared to controls ${ }^{(34,35)}$. Furthermore, in the same study, the recognised tumour marker cerbB-2 (erb) was found to be present in the saliva of breast cancer patients and absent in control subjects, possibly representing a more robust biomarker of breast cancer than CA15- $3^{(35)}$. Another cancer antigen, CA125, which is frequently used as a serum marker of ovarian cancer, was also found to be elevated in the saliva of patients with ovarian cancer. In these studies, salivary levels were found to be a better diagnostic marker of the disease than serum values ${ }^{(36)}$. A later study was able to use the diurnal rhythm in salivary CA125 levels to direct successfully a therapeutic antitumourigenic agent against ovarian cancer ${ }^{(37)}$. EGF (as discussed earlier) is present in the saliva of humans and fulfils a growth and repair role in the oral cavity. EGF overexpression is thought to be linked to tumourigenesis. Salivary EGF was found to be significantly raised in women with active and nonactive breast cancer compared to healthy women ${ }^{(38)}$. The observation that systemic diseases can influence the circadian rhythm of secreted salivary components was used in one study, where diurnal salivary cortisol 
measurements were used to predict breast cancer survivability using the slope of diurnal cortisol as a predictive marker ${ }^{(39)}$.

\section{Viral Diseases (exclusive of HIV)}

The antibody response to infection is the basis for many diagnostic tests in virology. Saliva contains immunoglobulins that originate from two sources: the salivary glands and serum. The predominant immunoglobulin in saliva is secretory $\operatorname{IgA}(\operatorname{sg} \mathrm{A})$, which is derived from plasma cells in the salivary glands, and constitutes the main specific immune defense mechanism in saliva. Although the minor salivary glands play an important role in sIgA-mediated immunity of the oral cavity, cells in the parotid and submandibular glands are responsible for the majority of the $\operatorname{IgA}$ found in saliva ${ }^{(40,41)}$. In contrast, salivary $\operatorname{IgM}$ and $\operatorname{IgG}$ are primarily derived from serum via GCF, and are present in lower concentrations in saliva than is IgA. Antibodies against viruses and viral components can be detected in saliva and can aid in the diagnosis of acute viral infections, congenital infections, and reactivation of infection ${ }^{(42) .}$

Saliva was found to be a useful alternative to serum for the diagnosis of viral hepatitis. Acute hepatitis A (HAV) and hepatitis B (HBV) were diagnosed based on the presence of IgM antibodies in saliva. The ratio of IgM to IgG anti-HAV antibody correlated with the time interval from onset of infection ${ }^{(43) . ~ F u r t h e r, ~ s a l i v a r y ~}$ antibody levels were used for the detection of infected individuals in a school outbreak of HAV ${ }^{(44,45)}$. Saliva has also been utilized to detect very low levels of antibodies to HAV, which, for example, are associated with vaccine-induced immunity.

Comparison of serum and saliva levels of antibody to HAVrevealed excellent agreement (sensitivity = $98.7 \%$ and specificity $=99.6 \%{ }^{(46)}$. Similarly, analysis of saliva provided a highly sensitive and specific method for the diagnosis of viral hepatitis B and $\mathrm{C}^{(47)}$. Analysis of oral fluid samples collected with Orasure ${ }^{\circledR}$ provided an excellent method for the diagnosis of viral hepatitis B and C.Sensitivity and specificity of $100 \%$ for the detection of antibodies for both diseases in oral fluid in comparison with serum antibodies were reported ${ }^{(48) .}$ Saliva has also been used for screening for hepatitis B surface antigen (HbsAg) in epidemiological studies. Comparing the detection of HbsAg in saliva with that in serum by means of a commercially available serological kit yielded a sensitivity of $92 \%$ and specificity of $86.8 \%{ }^{(49)}$. Saliva may also be used for determining immunization and detecting infection with measles, mumps, and rubella ${ }^{(50,51)}$. The detection of antibodies in oral fluid samples produced sensitivity and specificity of $97 \%$ and $100 \%$ for measles, $94 \%$ and $94 \%$ for mumps, and $98 \%$ and $98 \%$ for rubella, respectively, in comparison with detection of serum antibodies for these viruses ${ }^{(52)}$. For newborn infants, the salivary $\operatorname{IgA}$ response was found to be a better marker of rotavirus (RV) infection than the serum antibody response. Neonatal RV infection elicited specific mucosal antibody response which persisted for at least 3 months. However, a similar systemic immune response could not be observed, possibly due to interference by maternal antibody.

The authors proposed that saliva, rather than serum, can be used to monitor the immune response to vaccination and infection with $\mathrm{RV}^{(53)}$ The shedding of herpesviruses (human herpesvirus -8 , cytomegalovirus, and Epstein-Barr virus) in nasal secretions and saliva of infected patients has been reported . Other investigators suggested that reactivation of herpes simplex virus type-1 (HSV-1) is involved in the pathogenesis of Bell's palsy and reported that PCR-based identification of virus in saliva is a useful method for the early detection of HSV-1 reactivation in patients with Bell's palsy. The shed HSV-1 virus was detected in $50 \%$ of patients with Bell's palsy in comparison with $19 \%$ in healthy controls ${ }^{(54)}$. Dengue is a mosquito-transmitted viral disease. Primary infection of the virus may lead to a self-limiting febrile disease, and secondary infection may cause serious complications like dengue hemorrhagic fever or dengue shock syndrome. Salivary levels of anti-dengue $\operatorname{IgM}$ and IgG demonstrated sensitivity of $92 \%$ and specificity of $100 \%$ in the diagnosis of primary and secondary infection, and salivary levels of $\mathrm{IgG}$ proved useful in differentiating between primary and secondary infection ${ }^{(55) .}$ Saliva was also found to be a reliable alternative to serum for identification of the antibody to parvovirus B 19. Sensitivity of $100 \%$ and specificity of $95 \%$ were observed for the detection of infected individuals at a primary school ${ }^{(56) .}$

\section{HIV}

Studies have demonstrated that the diagnosis of infection with the human immunodeficiency virus (HIV) based on specific antibody in saliva is equivalent to serum in accuracy, and therefore applicable for both clinical use and epidemiological surveillance ${ }^{(57) .}$ Antibody to HIV in whole saliva of infected individuals, which

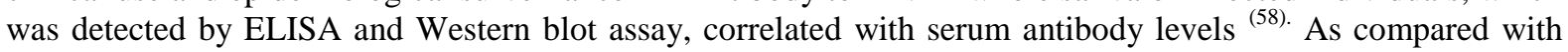
serum, the sensitivity and specificity of antibody to HIV in saliva for detection of infection are between $95 \%$ and $100 \%$. Salivary IgA levels to HIV decline as infected patients become symptomatic. It was suggested that detection of IgA antibody to HIV in saliva may, therefore, be a prognostic indicator for the progression of HIV infection (59). Analysis of antibody in saliva as a diagnostic test for HIV (or other infections) offers several distinctive advantages when compared with serum. Saliva can be collected non-invasively, which eliminates the 
risk of infection for the health care worker who collects the blood sample. Furthermore, viral transmission via saliva is unlikely, since infectious virus is rarely isolated from saliva. Saliva collection also simplifies the diagnostic process in special populations in whom blood drawing is difficult, i.e., individuals with compromised venous access (e.g., injecting drug users), patients with hemophilia, and children ${ }^{(60)}$. Several salivary and oral fluid tests have been developed for HIV diagnosis. Orasure ${ }^{\circledR}$ is a testing system that is commercially available in the United States and can be used for the diagnosis of HIV. The test relies on the collection of an oral mucosal transudate (and therefore $\mathrm{IgG}$ antibody). IgG antibody to the virus is the predominant type of anti-HIV immunoglobulin . Different oral pathologic lesions, which are relatively common in HIV-infected individuals, do not appear to influence the results ${ }^{(61) .}$ In conclusion, collection and analysis of saliva offer a simple, safe, well-tolerated, and accurate method for the diagnosis of HIV infection

\section{Concluding Remarks}

The repertoire of salivary biomarkers is ever expanding. Recently, Salimetrics® introduced a kit for measuring human salivary C-type reactive protein (CRP), which is commonly used as a biomarker of cardiovascular-related inflammation. From our own studies, we have reported that the glucocorticoid regulated anti-inflammatory substance Annexin-A1 is present in human saliva and furthermore demonstrates a positive correlation with the diurnal rhythm of salivary cortisol[218]. The success of saliva as a diagnostic media is guaranteed, particularly for substances that reflect or can be directly correlated with systemic analytes. The degree of that success is likely to depend on the introduction of mobile diagnostic devices that have the capacity to measure multiple analytes in a rapid, cost-effective manner. With many such technologies currently under development, the future of salivary diagnostics is looking very bright.

\section{References}

[1]. The American Academy of Periodontology. The pathogenesis of periodontal disease (position paper).Journal of Periodontology 1999;70:457- 70 .

[2]. Beck JD, Offenbacher S. Systemic effects of periodontitis: Epidemiology of periodontal disease and cardiovascular disease. Journal of Periodontology 2005;76:2089-2100.

[3]. Streckfus C, Bigler L, Tucci M, Thigpen JT. A preliminary study of CA15-3, cerbB-2, epidermal growth factor receptor, cathepsin-D, and p53 in saliva among women with breast carcinoma. Cancer Investigation 2000;18:101-09.

[4]. Li Y, St John MA, Zhou X, Kim Y, Sinha U, Jordan RCK, et al. Salivary transcriptome diagnostics for oral cancer detection.Clinical Cancer Research 2004;10: 8442-50.

[5]. Bratthall D, Hansel Petersson G. Cariogram - a multifactorial risk assessment model for a multifactorial disease. Community Dental and Oral Epidemiology 2005;33:256-64.

[6]. Hu S, Zhou M, Jiang J, Wang J, Elashoff D, Gorr S, et al. Systems biology analysis of Sjogren's syndrome and mucosa associated lymphoid tissue lymphoma in parotid glands. Arthritis and Rheumatism 2009;60:81-92.

[7]. Balwant R, Sammi K, Rajnish J, Suresh CA. Biomarkers of periodontitis in oral fluid. Journal of Oral Sciences 2008;50(1):53-56.

[8]. Hodinka RL, Nagashunmugam T, Malamud D. Detection of human immunodeficiencyvirus antibodies in oral fluids. Clinical Diagnosis, Laboratory and Immunology 1998;5:419 26.

[9]. Grinnobile WV, Beikler T, Kinney JS, Ramseier CA, Morelli T, Wong DT. Saliva as a diagnostic tool for periodontal disease: Current state and future directions. Periodontol 2000. 2009;50:52-64

[10]. Delacroix DL, Dive C, Rambaud JC, Vaerman JP. IgA subclasses in various secretions and in serum. Immunology. 1982;47:383-5

[11]. Guven O, De Visscher JG. Salivary IgA in periodontal disease. J Periodontol. 1982;53:334-5

[12]. Sandholm L, Gronblad E. Salivary immunoglobulins in patients with juvenile periodontitis and their healthy siblings. J Periodontol. 1984;55:9-12

[13]. Eggert FM, Maenz L, Tam YC. Measuring the interaction of human secretory glycoproteins to oral bacteria. J Dent Res. 1987;66:610-2

[14]. Groenink J, Ligtenberg AJ, Veerman EC, Bolscher JG, Nieuw Amerongen AV. Interaction of the salivary lowmolecular- weight mucin (MG2) with Actinobacillus actinomycetemcomitans. Antonie Van Leeuwenhoek 1996: 70: $79-87$.

[15]. Jalil RA, Ashley FP, Wilson RF. The relationship between 48-h dental plaque accumulation in young human adults and the concentrations of hypothiocyanite, _free_and_total_ lysozyme, lactoferrin and secretory immunoglobulin A in saliva. Arch Oral Biol 1992: 37: 23-28.

[16]. Groenink J, Walgreen-Weterings E, Nazmi K, Bolscher JG, Veerman EC, van Winkelhoff AJ, Nieuw Amerongen AV. Salivary lactoferrin and low-Mr mucin MG2 in Actinobacillus actinomycetemcomitans-associated periodontitis. J Clin Periodontol 1999: 26: $269-275$.

[17]. Gusman H, Travis J, Helmerhorst EJ, Potempa J, Troxler RF, Oppenheim FG. Salivary histatin 5 is an inhibitor of both host and bacterial enzymes implicated in periodontal disease. Infect Immun 2001: 69: 1402-1408.

[18]. Helmerhorst EJ, Oppenheim FG. Saliva: a dynamic proteome.J Dent Res 2007: 86: 680-693.

[19]. Guven Y, Satman I, Dinccag N, Alptekin S. Salivary peroxidise activity in whole saliva of patients with insulindependent (type-1) diabetes mellitus. J Clin Periodontol 1996: 23: 879-881.

[20]. Schenkels LC, Veerman EC, Nieuw Amerongen AV. Biochemical composition ofhuman saliva in relation to other mucosal fluids. Crit Rev Oral Biol Med 1995;6(2):161-75.

[21]. Balwant R, Sammi K, Rajnish J, Suresh CA.Biomarkers of periodontitis in oral fluid. J Oral Sci. 2008;50(1):53-56.

[22]. Kaufman E, Lamster IB. The diagnosticapplications of saliva: a review. Crit Rev OralBiol Med. 2002;13:197-212.

[23]. Miller CS, King CP Jr, Langub MC, Kryscio RJ, Thomas MV. Salivary biomarkers ofexisting periodontal disease: a cross sectional study. J Am Dent Assoc. 2006;137:322-329. de Jong EP, Xie H, Onsongo G, Stone MD, Chen X-B, et al. (2010) Quantitative

[24]. Proteomics Reveals Myosin and Actin as Promising Saliva Biomarkers for Distinguishing Pre-Malignant and Malignant Oral Lesions. PLoS ONE. 2010;5(6): e11148. 
[25]. Hu S, Arellano M http://clincancerres.aacrjournals.org/content/14/ 19/6246. Short - target-1, Boontheung P, Wang J, Zhou H, Jiang J et al. Salivary Proteomics for Oral Cancer Biomarker Discovery. Clin Cancer Res. 2008;14: 6246.

[26]. Maie AR, Yang Li, Xiaofeng Zhou, Paul Denny, Chih-Ming Ho,Carlo Montemagno.Interleukin 6 and Interleukin 8 as Potential Biomarkers for Oral Cavity and Oropharyngeal Squamous Cell Carcinoma. Arch Otolaryngol Head Neck Surg. 2004;130:929-935.

[27]. Mandel, I.D. (1993) Salivary diagnosis: promises, promises. Ann. N. Y. Acad. Sci. 694, 1-10.

[28]. Miller, S.M. (1994) Saliva testing--a non-traditional diagnostic tool. Clin. Lab. Sci. 7(1), 39-44.

[29]. Hu, S., Xie, Y., Ramachandran, P., Ogorzalek Loo, R.R., Li, Y., Loo, J.A., and Wong, D.T. (2005) Large-scale identification of proteins in human salivary proteome by liquid chromatography/mass spectrometry and two-dimensional gel electrophoresis-mass spectrometry. Proteomics 5(6), 1714-1728.

[30]. Li, Y., Zhou, X., St John, M.A., and Wong, D.T. (2004) RNA profiling of cell-free saliva using microarray technology. J. Dent. Res. 83(3), 199-203.

[31]. Li, Y., Elashoff, D., Oh, M., Sinha, U., St John, M.A., Zhou, X., Abemayor, E., and Wong, D.T. (2006) Serum circulating human mRNA profiling and its utility for oral cancer detection. J. Clin. Oncol. 24(11), 1754-1760.

[32]. Segal, A. and Wong, D.T. (2008) Salivary diagnostics: enhancing disease detection and making medicine better. Eur. J. Dent. Educ. 12(Suppl 1), 22-29.

[33]. Gau, V. and Wong, D. (2007) Oral fluid nanosensor test (OFNASET) with advanced electrochemical-based molecular analysis platform. Ann. N. Y. Acad. Sci. 1098, 401-410.

[34]. Streckfus, C., Bigler, L., Tucci, M., and Thigpen, J.T. (2000) A preliminary study of CA15-3, c-erbB-2, epidermal growth factor receptor, cathepsin-D, and p53 in saliva among women with breast carcinoma. Cancer. Invest. 18(2), 101-109.

[35]. Streckfus, C. and Bigler, L. (2005) The use of soluble, salivary c-erbB-2 for the detection and post-operative follow-up of breast cancer in women: the results of a five-year translational research study. Adv. Dent. Res. 18(1), 17-24.

[36]. Chen, D.X., Schwartz, P.E., Li, X.G., and Yang, Z. (1988) Evaluation of CA 125 levels in differentiating malignant from benign tumors in patients with pelvic masses. Obstet. Gynecol. 72(1), 23-27.

[37]. Cornélissen, G., Halberg, F., Halberg, E., Bingham, C., Haus, E., Bast, R.C., Jr., Fujii, S., Long, H.J., 3rd, Halberg, F., and Tamura, K. (1992) Toward a chronotherapy of ovarian cancer. Part III: Salivary CA125 for chronochemotherapy by efficacy. Chronobiology 19(3-4), 131-149.

[38]. Navarro, M.A., Mesía, R., Díez-Gibert, O., Rueda, A., Ojeda, B., and Alonso, M.C. (1997) Epidermal growth factor in plasma and saliva of patients with active breast cancer and breast cancer patients in follow-up compared with healthy women. Breast Cancer Res. Treat. 42(1), 83-86.

[39]. Sephton, S.E., Sapolsky, R.M., Kraemer, H.C., and Spiegel, D. (2000) Diurnal cortisol rhythm as a predictor of breast cancer survival. J. Natl. Cancer Inst. 92(12), 994-1000.

[40]. Bienenstock J, Befus AK, McDermott M (1980). Mucosal immunity. Monogr Allergy 16:1-18.

[41]. Korsrud FR, Brandtzaeg P (1980). Quantitative immunohistochemistry of immunoglobulin- and J-chain-producing cells in human parotid and submandibular salivary glands. Immunology 39:129-140

[42]. Mortimer PP, Parry JV (1988). The use of saliva for viral diagnosis and screening. Epidemiol Infect 101:197-201.

[43]. Parry JV, Perry KR, Panday S, Mortimer PP (1989). Diagnosis of hepatitis A and B by testing saliva. J Med Virol 28:255-260.

[44]. Bull AR, Kimmance KJ, Parry JV, Perry KR (1989). Investigation of an outbreak of hepatitis A simplified by salivary antibody testing. Epidemiol Infect 103:371-376.

[45]. Stuart JM, Majeed FA, Cartwright KA, Room R, Parry JV, Perry KR, et al. (1992). Salivary antibody testing in a school outbreak of hepatitis A. Epidemiol Infect 109:161-166.

[46]. Ochnio JJ, Scheifele DW, Ho M, Mitchell LA (1997). New, ultrasensitive enzyme immunoassay for detecting vaccine- and disease-induced hepatitis A virus-specific immunoglobulin G in saliva. J Clin Microbiol 35:98-101.

[47]. El-Medany OM, El-Din Abdel Wahab KS, Abu Shady EA, Gad El-Hak N (1999). Chronic liver disease and hepatitis C virus in Egyptian patients. Hepatogastroenterology 46:1895-1903.

[48]. Thieme T, Yoshihara P, Piacentini S, Beller M (1992). Clinical evaluation of oral fluid samples for diagnosis of viral hepatitis. $J$ Clin Microbiol 30:1076-1079.

[49]. Chaita TM, Graham SM, Maxwell SM, Sirivasin W, Sabchareon A, Beeching NJ (1995). Salivary sampling for hepatitis B surface antigen carriage: a sensitive technique suitable for epidemiological studies. Ann Trop Paediatr 15:135-139.

[50]. Friedman MG (1982). Radioimmunoassay for the detection of virus-specific IgA antibodies in saliva. J Immunol Meth 54:203211.

[51]. Perry KR, Brown DW, Parry JV, Panday S, Pipkin C, Richards A (1993). Detection of measles, mumps, and rubella antibodies in saliva using antibody capture radioimmunoassay. J Med Virol 40:235-240.

[52]. Thieme T, Piacentini S, Davidson S, Steingart K (1994).Determination of measles, mumps, and rubella immunization status using oral fluid samples. J Am Med Assoc 272:219-221.

[53]. Jayashree S, Bhan MK, Kumar R, Raj P, Glass R, Bhandari N (1988). Serum and salivary antibodies as indicators of rotavirus infection in neonates. $J$ Infect Dis 158:1117-1120.

[54]. Furuta Y, Fukuda S, Chida E, Takasu T, Ohtani F, Inuyama Y, et al. (1998). Reactivation of herpes simplex virus type 1 in patients with Bell's palsy. J Med Virol 54:162-166.

[55]. Cuzzubbo AJ, Vaughn DW, Nisalak A, Suntayakorn S, Aaskov J, Devine PL (1998). Detection of specific antibodies in saliva during dengue infection. J Clin Microbiol 36:3737-3739.

[56]. Rice PS, Cohen BJ (1996). A school outbreak of parvovirus B19 infection investigated using salivary antibody assays. Epidemiol Infect 116:331-338.

[57]. Malamud D (1997). Oral diagnostic testing for detecting human immunodeficiency virus-1 antibodies: a technology whose time has come. Am J Med 102:9-14

[58]. Holmström P, Syrjänen S, Laine P, Valle SL, Suni J (1990). HIV antibodies in whole saliva detected by ELISA and Western blot assays. J Med Virol 30:245-248.

[59]. Matsuda S, Oka S, Honda M, Takebe Y, Takemori T (1993).Characteristics of IgA antibodies against HIV-1 in sera and saliva from HIV-seropositive individuals in different clinical stages. Scand J Immunol 38:428-434.

[60]. Archibald DW, Farley JJ, Hebert CA, Hines SE, Nair P, Johnson JP (1993). Practical applications for saliva in perinatal HIV diagnosis. Ann NY Acad Sci 694:195-201.

[61]. Emmons W (1997). Accuracy of oral specimen testing for human immunodeficiency virus. Am J Med 102:15-20.

[62]. Renshaw, D., Mancini, L., Flower, R., and Perretti, M. (2008) Salivary cortisol: a possible regulator of salivary annexin 1. Endocrine Abstracts $15 \mathrm{P} 330$. 